\title{
Gravity anomaly and crustal density structure in Jilantai rift zone and its adjacent region
}

\author{
Guiju Wu $\cdot$ Chongyang Shen $\cdot$ Hongbo Tan $\cdot$ Guangliang Yang
}

Received: 30 December 2015/Accepted: 24 June 2016/Published online: 6 August 2016

(C) The Author(s) 2016. This article is published with open access at Springerlink.com

\begin{abstract}
This paper deals with the interpretation of Bouguer gravity anomalies measured along a $250 \mathrm{~km}$ long Suhaitu-Etuokeqi gravity profile located at the transitional zone of the Alxa and Ordos blocks where geophysical characteristics are very complex. The analysis is carried out in terms of the ratio of elevation and Bouguer gravity anomaly, the normalized full gradient of a section of the Bouguer gravity anomaly $\left(G^{h}\right)$ and the crustal density structure reveal that (1) the ratio of highs and lows of elevation and Bouguer gravity anomaly is large between Zhengyiguan fault (F4) and Helandonglu fault (F6), which can be explained due to crustal inhomogeneities related to the uplift of the Qinghai-Tibet block in the northeast; (2) the main active faults correspond to the $G^{h}$ contour strip or cut the local region, and generally show strong deformation characteristics, for example the Bayanwulashan mountain front fault $(F 1)$ or the southeast boundary of Alxa block is in accord with the western change belt of $G^{h}$, a belt about $10 \mathrm{~km}$ wide that extends to about $30 \mathrm{~km}$; (3) YinchuanPingluo fault $(F 8)$ is the seismogenic structure of the Pingluo $M$ earthquake, and its focal depth is about $15 \mathrm{~km}$; (4) the Moho depth trend and Bouguer gravity anomaly variation indicates that the regional gravity field is strongly correlated with the Moho discontinuity.
\end{abstract}

Keywords Yinchuan-Helanshan uplift · Jilantai rift zone · Gravity profile $\cdot$ Bouguer gravity anomaly $\cdot$ Crustal density structure $\cdot$ Normalized full gravity gradient $\cdot$ Seismogenesis

G. Wu $(\varangle) \cdot$ C. Shen $\cdot$ H. Tan · G. Yang

The Key Laboratory of Earthquake Geodesy, Institute of

Seismology, China Earthquake Administration, Wuhan 430071, China

e-mail: wugjsky@126.com

\section{Introduction}

The Jilantai rift zone and its adjacent region are located at the border of the Ordos and Alxa blocks, with the stable Alxa block and Ordos block to the west and east, respectively, and in the middle of it is a tectonic deformation transitional belt. The previous research results in the area focus on the Helanshan-Yinchuan basin. Tongen and Jialiu (1982) analyzed the deep structure surrounding the North-South seismic belt and discussed the crust and upper mantle structure feature of the Helanshan-Liupanshan seismic zone. Chai et al. (2006) gave the blind fault activity characteristics in Yinchuan and the surrounding area comprehensively. Fang et al. (2009) studied the relationship between the Huanghe, Yinchuan, and Helanshandonglu faults and their shallow and deep structure using a deep seismic reflection method. Other researchers (Zheng 2011; Yin et al. 2013) then obtained the electrical structure of the Ordos block and JiangyuanNingxia region. All of this research has mainly focused on the deep seismic reflection method and magnetotelluric sounding method in the area, but there are few research findings based on gravity. There is also a lack of density structure research in the region.

Gravity profile detection has been widely used; we can obtain the surface gravity anomaly with high precision, small spacing, and crossing fault observation, and then invert the density distribution of the ground material and estimate the geological structure distribution in the crust and media deformation. For example, Halls and Mound (1998), and Nitescu and Halls (2002) established the faultdeveloping situation in the Kapuskasing structural zone with gravity profile and GPS data. Meng et al. (1990), Wang et al. (1997), and Yang et al. (2015) all found crustal block structures using gravity profile data and so on. 
With support from the project "China Seismic Array," we found the Suhait-Etuokeqi gravity profile of about $250 \mathrm{~km}$ (the blue star line is shown in Fig. 1), which spans the Alxa block, Jilantai rift zone, Helanshan uplift, Yinchuan basin, and Ordos block. In this article, we analyze the distribution features of the gravity anomaly along the profile, which reflects the characteristics of the density of the hierarchical structure of the crust.

\section{Geological setting}

The research area is located in the northwest of Ordos, as shown in Fig. 1. The Jilantai rift zone is mainly in a NorthNorth-West direction and is inside the north China Craton Plate tectonic deformation belt, where its tectonic movement is associated with the mutual movement of the Ordos and Alxa blocks. Since the Cenozoic era, the change of stress in the north China has made the tensions of the Alxa and Ordos blocks affect each other, which means that the region's tectonic movement has priority over the stretching deformation within the mainland (Hong et al. 1987; Yin and Harrison 2000; Xu et al. 2000; Mao and Yao 1982). Most of the research area is covered by Quaternary sediments. The covering of quaternary sediments is very serious in the Alxa block part and the outcrop conditions are poor, where it is mainly Variscan. The faults are very developed, and they distribute mainly between $106^{\circ} \mathrm{E}$ and $107{ }^{\circ} \mathrm{E}$ in North-East direction. Earthquake activity is strong in this region; the Pingluo $M 8$ earthquake occurred in 1739, but its seismogenic structure has been controversial. Mao and Yao (1982), Li and Wan (1984) and Wu et al.
(2015), and many other scholars think that the earthquake seismogenic structure is the Yinchuan blind fault, but others believe the active Helandonglu fault is the seismogenic structure (Fang et al. 2009; Lei et al. 2015; Wang et al. 2015). The current understanding of the blocks is obscure or ambiguous, which makes it difficult to analyze the mutual block movement and deformation in-depth. Therefore, a reasonable explanation for the current activity difference between the deep fault of the block boundary and the secondary faults in the block cannot be found.

\section{Gravity anomaly}

\subsection{Regional gravity data}

Figure 2 shows the regional Bouguer gravity anomaly. It is compiled in terms of the 1:4 million Chinese Bouguer gravity anomaly, and it reflects the total substance distribution formed by tectonic deformation over a long time between the Alxa and Ordos blocks. On the whole, the spreading of the regional gravity anomaly is from low to high to low. There is a low anomaly zone between $F 1$ and the $F 6$, where it passes the Jilantai rift zone. Between the Helanshandonglu fault and the Yellow river fault, there is a local high gravity anomaly, mainly located in the Pingluo area; the range of the anomaly value is from -146 to $-122 \mathrm{mGal}$. The directions of the faults in the research area are mainly consistent with the strike of the contour of the Bouguer gravity, for example, the Bayanwulashan fault, Helanshandonglu fault, Yinchuan blind fault, and Yellow river fault.
A

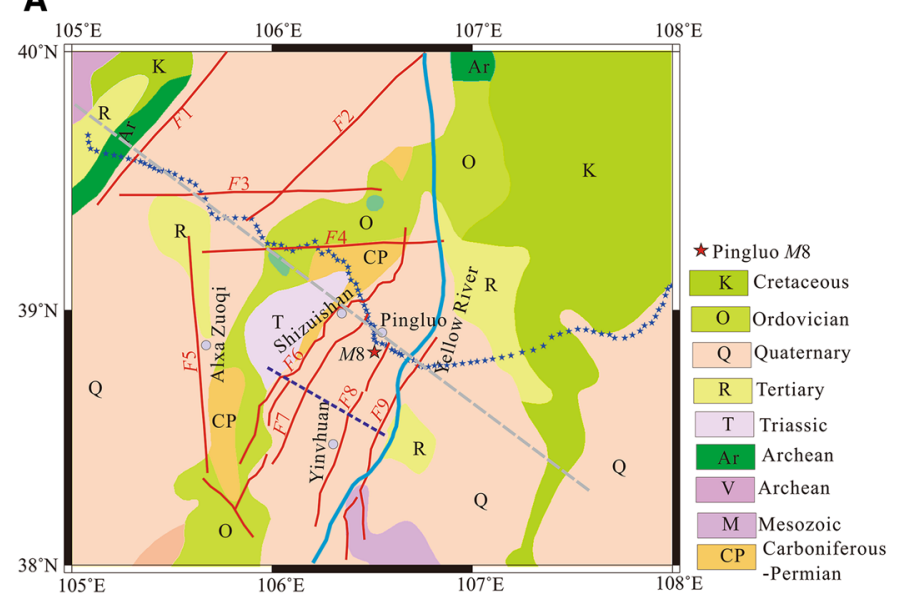

B

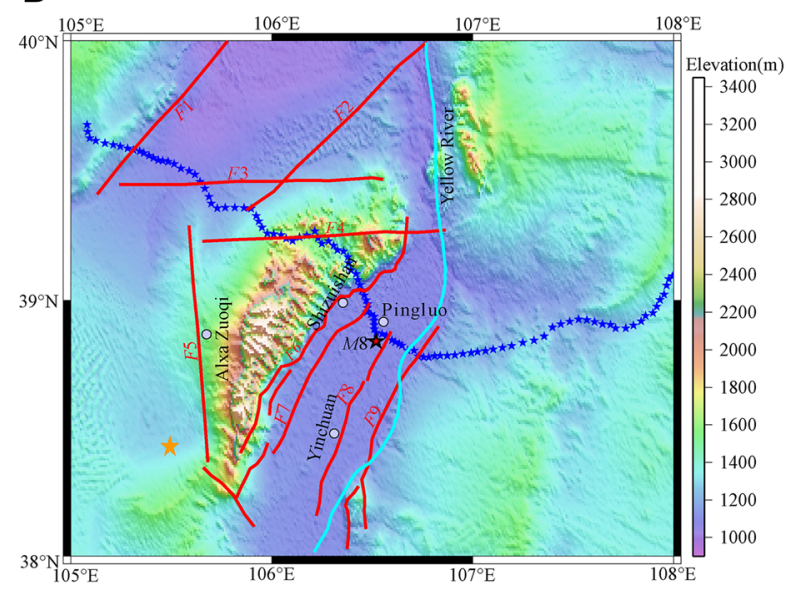

Fig. 1 a Regional geological structure background. b Regional elevation map. Blue stars are the measuring points, the dotted blue line is a deep seismic reflection profile (Fang et al. 2009), the orange star is an absolute gravity station what is to control the relative gravity. F1 Bayanwulashan fault, F2 Dengkou-Benjing fault, F3 Hetun-Benjing fault, F4 Zhengyiguan fault, F5 Bapuhaote fault, F6 Helandonglu fault, F7 Chonggang-Luhuatai fault, $F 8$ Yinchuan blind fault, $F 9$ Yellow River fault. The gray dotted line is the projection of the profile in a 


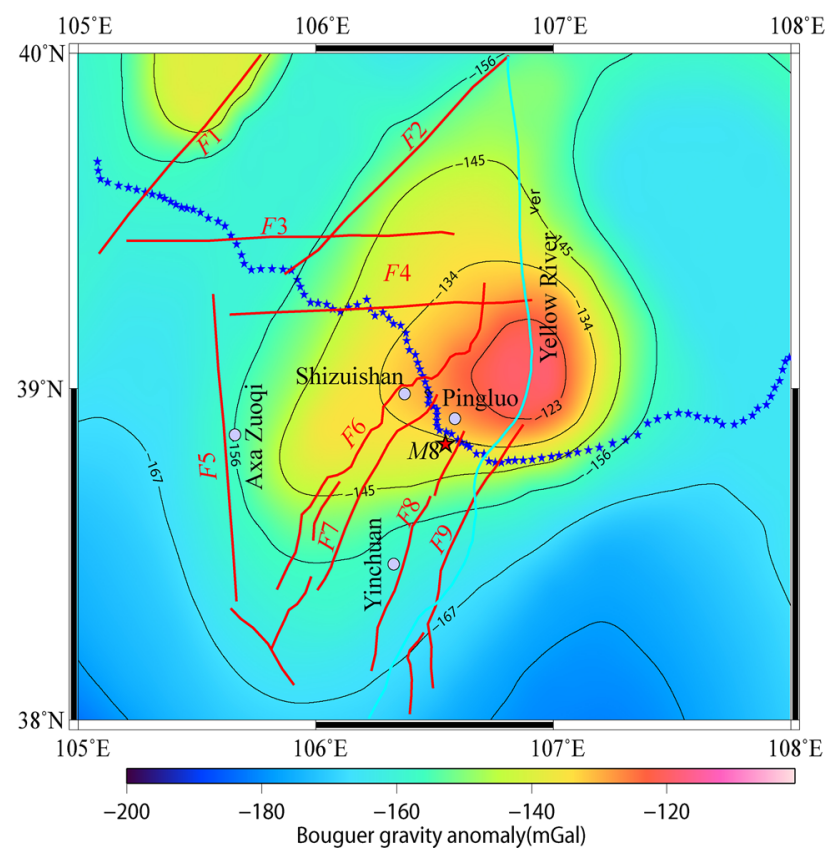

Fig. 2 Region of the gravity Bouguer anomaly in the research area

\subsection{Profile of gravity anomaly}

The profile is nearly in a east-west direction; the number of measuring points is 109 , and the length is about $250 \mathrm{~km}$. We obtained the observation gravity data on the basis of the WGS84 vertical coordinate system after deleting drift and tide, and using adjustment processes, the gravity meter is CG-5. The point value accuracy is above $20 \times 10^{-8} \mathrm{~m} /$ $\mathrm{s}^{2}$. In order to obtain the Bouguer gravity anomaly, we must correct the observation data, such as a normal gravity field correction, atmospheric correction, elevation correction, the middle layer correction, and terrain correction. In this paper, the ASTER GDEM data are used in the terrain correction.

In Fig. 3, the red curve is the profile gravity anomaly; the blue curve is the regional gravity anomaly, which is taken directly from the regional Bouguer gravity anomaly (Fig. 2). The general trend of the profile of the gravity anomaly is low-high-low. The result for the profile of the Bouguer gravity anomaly shows that the variation range of the Bouguer gravity anomaly is from -210 to $-155 \mathrm{mGal}$, and the Bouguer gravity anomaly changes greatly at $F 1$, $F 6$, and $F 9$. The differences on both sides of $F 1, F 6$, and $F 9$ are about $25 \mathrm{mGal}, 45 \mathrm{mGal}$, and $36 \mathrm{mGal}$, respectively. For the region of the Bouguer gravity anomaly along the direction of the profile, the overall trend is similar to the profile of the Bouguer gravity anomaly trend. But their trends are oppositive in the Pingluo area, where the profile of the Bouguer anomaly is low, and the other is high. In the 1990s, the Ministry of Geology and Mineral Resources found that the Pingluo area is rich in coal. With the development of society, large areas of coal have been mined and the mining depth is thousands of meters. Generally speaking, the density of a coal mine is about $1.1-1.7 \mathrm{~g} / \mathrm{cm}^{3}$, but the average density is $2.67 \mathrm{~g} / \mathrm{cm}^{3}$ when we carry out terrain correction. Therefore, the density of $2.67 \mathrm{~g} / \mathrm{cm}^{3}$ is unfit for terrain correction. Finally, we found the near-region terrain correction $(0-2 \mathrm{~km})$, again between 6 and $46 \mathrm{~km}$ along the profile, and the average density is $1.3 \mathrm{~g} / \mathrm{cm}^{3}$; the green curve in Fig. 3 shows this result. Comparing the profile and regional gravity anomaly, the trends of both are similar.

\subsection{Spatial relations between Bouguer gravity anomaly and elevation}

The land Bouguer gravity anomaly and terrain elevation are often negatively related, which can be explained by the Airy isostatic compensation hypothesis. That is to say, the "surplus" material above the geoid can be filled by the "losses" of material of the interior earth relative to a certain Earth model. The closer the negative correlation is, the more perfect the isostatic compensation is. The corresponding characteristics of the quality of profit and loss of isostatic compensation are not the same, because the material composition, density structure, and tectonic layering of tectonic units with different physical properties and shapes lead to related degrees of the Bouguer gravity value changing when the terrain is different (Peng and Min 1985, 1997). At the same time, the trend demarcation point or line of the Bouguer anomaly and elevation statistical relationship may be the transmutative or a strongly active part of the crust.

The ratio of the elevation and Bouguer anomaly along the gravity profile is the peach line with circles in Fig. 3, and it can be divided into two sections in the west and east sides of $F 6$. The profile between elevation and the Bouguer anomaly is generally a negative correlation, which means that the quality is overall a loss from Suhait to Etuokeqi. The ratio of the ups and downs is large in the west of the profile, especially between $F 4$ and $F 6$, which can be explained by the fact that the crustal material in this section is inhomogeneous and different; it is associated with the cutting of multiple faults. In the east, the ratio of ups to downs is more gradual than in the west. The strong deformation zone is located at the Helanshan uplift-Jilantai rift area from east to west, which is inside the North China Craton plate tectonic deformation belt. Since the Cenozoic era, the main tectonic movement of the region is the stretching deformation within the mainland (Hong et al. 1987; Yin and Harrison 2000; Xu et al. 2000; Li and Wan 1984; Liu et al. 2010). The Jilantai-Yinchuan rift zone is the main part of the north segment of the North-South 


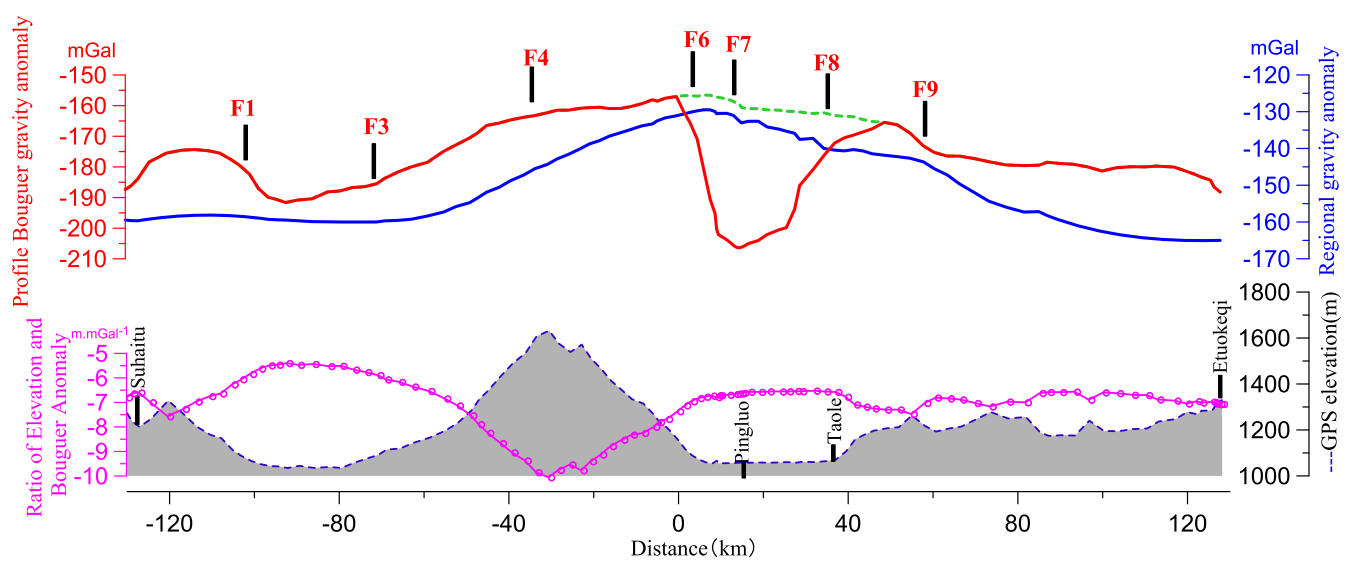

Fig. 3 Bouguer gravity anomaly of the profile, its corresponding GPS elevation and the ratio of the elevation and Bouguer anomaly along the gravity profile

seismic belt, and is pushed by the Qinghai-Tibet block in the northeast, which is very active.

\subsection{Normalized full gravity gradient imaging}

The normalized full gradient (NFG) method was proposed in the mid-1960s by Berezkin and Buketov (1965; Berezkin 1967), and was generally used for the downward continuation of the potential field data. The method eliminates the side oscillations which appeared on the continuation curves when passing through an anomalous body depth (Dondurur 2005; Sindirgi et al. 2008; Aghajani et al. 2009; Abedi et al. 2012). The NFG operator $G^{h}(x, z)$ constitutes the basic concept of the NFG method and is defined in two dimensions as

$$
G^{h}(x, z)=\frac{\sqrt{\left(\frac{\partial \mathrm{w}(x, z)}{\partial x}\right)^{2}+\left(\frac{\partial \mathrm{w}(x, z)}{\partial z}\right)^{2}}}{\frac{1}{M+1} \sum_{i=0}^{M} \sqrt{\left(\frac{\partial \mathrm{w}(x, z)}{\partial x}\right)^{2}+\left(\frac{\partial \mathrm{w}(x, z)}{\partial z}\right)^{2}}}
$$

where $\mathrm{w}(x, z)$ is the function defining the geophysical field along the $x$ axis, $M$ is the number of observation points, $\partial \mathrm{w} / \partial x$ and $\partial \mathrm{w} / \partial z$ are derivatives of the function $\mathrm{w}(x, z)$ with respect to $x$ and $z$, respectively.

The profile gravity anomaly is a linear interpolation with $1 \mathrm{~km}$, the harmonic number is 40 , the plane on which the downward continuation is $1 \mathrm{~km}$, and we obtain the image of the NFG along the profile shown in Fig. 4. The main characteristics of the gravity profile are that the distribution of $G^{h}$ is complex in the upper crust from west to east along the profile and there are several transition zones of high and low $G^{h}$, located at about $-110,-85,-30,-5,20,50$, and $70 \mathrm{~km}$. The value of the $G^{h}$ change is caused by the difference of the subsurface densities. The Suhait-Etuokeqi profile traverses $F 1, F 3, F 4, F 6, F 9$, and the north end of $F 7$ and $F 8$.
The dip angles of these faults are about $60^{\circ}$. The fault strike of $F 1$ is North-East, $F 4$ is east-west, the fault strike of $F 6$, $F 8$, and $F 9$ is North-North-East, $F 1$ and $F 4$ are inclined to the south, $F 6$ is inclined to the South-East, and $F 8$ and $F 9$ are inclined to the NW. By analyzing the results of the NFG and of the background structure and geology, we found that the transition zones of the NFG are consistent with the distribution of faults, and their dip angles also coincide with each other, especially $F 6, F 7, F 8$, and $F 9$.

\section{Crustal density structure}

The Bouguer gravity anomaly is caused by the uneven distribution of crustal material. We can obtain the density distribution model underground by inversion of the Bouguer gravity anomaly. If we use a no-prior constrained information method to invert gravity, we can detect the petrophysical distribution in the subsurface, and then obtain the difference characteristics of the crust density distribution, for example, Euler deconvolution inversion, Wiener decomposition, Residual density imaging method and so on. Based on the study mentioned above, inverting gravity with the help of other geological and geophysical information can further obtain a credible crustal structure distribution model. Using the NFG method the article first gives the preliminary crustal structure result of the profile, then, combining with the result of an artificial earthquake, inverts the profile gravity anomaly, which is the chosen method to study the characteristics of the crustal density distribution along the profile.

First, the initial model is established according to the characteristics of the crust in the vertical layered and lateral block. The profile can be divided into three segments in the landscape, the Alxa block, Jilantai transitional zone, and 


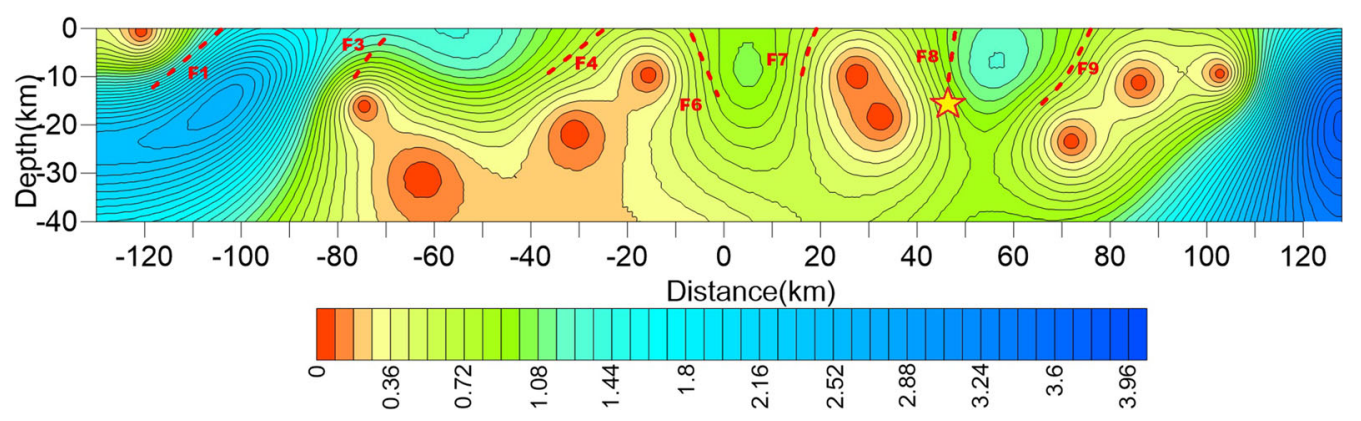

Fig. 4 The image of the normalized full gradient of the gravity profile

the Ordos block. For the crustal layers readers may refer to the results of deep seismic reflection and crust1.0. There are no deep seismic reflection results because of the poor environment. Therefore, on the basis of the results given by Fang et al. (2009), Lei et al. (2015) and Wang et al. (2014) and crust1.0, the initial model is established (Table 1). In terms of the above, applying a human-computer interaction method inverts the profile gravity anomaly, and gives the layered structure of the profile density model, which is shown in Fig. 5.

Figure 5 shows that the section of the crust density stratified model is divided into three layers as a whole. The upper crust includes the Earth's overburden. The average density of the upper crust is $2.73 \mathrm{~g} / \mathrm{cm}^{3}$; its bottom depth is $11-14 \mathrm{~km}$ (the average depth is about $12 \mathrm{~km}$ ); to the west of $F 1$, the depth undulation is obvious. The density of the overburden is $2.5 \mathrm{~g} / \mathrm{cm}^{3}$; its average bottom buried depth is approximately $1.5 \mathrm{~km}$, the thickness is generally no more than $2 \mathrm{~km}$, the buried depth is deeper and almost-flat between $F 4$ and $F 9$, and the thickness becomes thin gradually from the middle to both ends of the profile. The density of the middle crust is $2.84 \mathrm{~g} / \mathrm{cm}^{3}$; its bottom depth is $22-26 \mathrm{~km}$, and its trend is similar to the bottom interface of the upper crust. The density of the lower crust is $2.93 \mathrm{~g} /$ $\mathrm{cm}^{3}$; the bottom interface depth (Moho depth) is 42-45 km, and it clearly shows that the depth is deep in the west and shallow in the east, that is to say the depth thins from west to east along the gravity profile. The density beneath the Moho is $3.3 \mathrm{~g} / \mathrm{cm}^{3}$.

Table 1 The initial model of the crust density

\begin{tabular}{ll}
\hline Layers & Depth/density \\
\hline The Earth's overburden & $0-4 \mathrm{~km} / 2.45 \mathrm{~g} / \mathrm{cm}^{3}$ \\
The upper crust & $\sim 20 \mathrm{~km} / 2.70 \mathrm{~g} / \mathrm{cm}^{3}$ \\
The middle crust & $\sim 29 \mathrm{~km} / 2.82 \mathrm{~g} / \mathrm{cm}^{3}$ \\
The lower crust & $\sim 50 \mathrm{~km} / 2.92 \mathrm{~g} / \mathrm{cm}^{3}$ \\
The upper mantle & $\sim / 3.32 \mathrm{~g} / \mathrm{cm}^{3}$ \\
\hline
\end{tabular}

\section{Discussion}

\subsection{Dynamics background analysis}

From the results of the modern tectonic stress field with the focal mechanism, the profile is mainly located in the tectonic deformation zone within the north China Craton Plate, where the Yinchuan-Helanshan uplift-Jilantai rift zone is; it is also in the transition zone of the Alxa block and Ordos block, a region in which priority is given to the Alxa block and Ordos block movement. Since the Cenozoic era, mutual tension between the Alxa and Ordos blocks has been produced under the effect of the transition of the stress field in north China, which makes the region's tectonic movement primarily a stretching deformation (Hong et al. 1987; Yin and Harrison 2000; $\mathrm{Xu}$ et al. 2000; Mao and Yao 1982). The abrupt change in the Bouguer gravity anomaly and the ratio of elevation and the Bouguer anomaly along the profile maybe the dominant regional stress field as a result of long-term effects.

From the observational results of the geotectonic movement and GPS, the material flow in the east of the Qinghai-Tibet plateau is shown to be a clockwise rotated horizontal motion around the eastern tectonic, which is mainly a southeast flow exhibited along the profile (Zhang et al. 2004). Under the northeast continuous pushing of the Indian plate, material in the Qinghai-Tibet plateau in the western part of the section along the Alxa block is a clockwise lateral extrusion, and the NE-E-SE effect makes a continued eastward migration. The northeast movement of Ordos is at a rate of $2-4 \mathrm{~mm} / \mathrm{a}$ (Xu et al. 2000) relative to stable Alxa block, this maybe one of the reasons why the gravity anomaly gradient zone forms between $F 4$ and $F 9$ on the Suhait-Etuokeqi profile. At the same time, on the effect of the uplift and the surrounding extension of the Qinghai-Tibet block, the crust thickness is gradually thinning from west to east along the profile. 

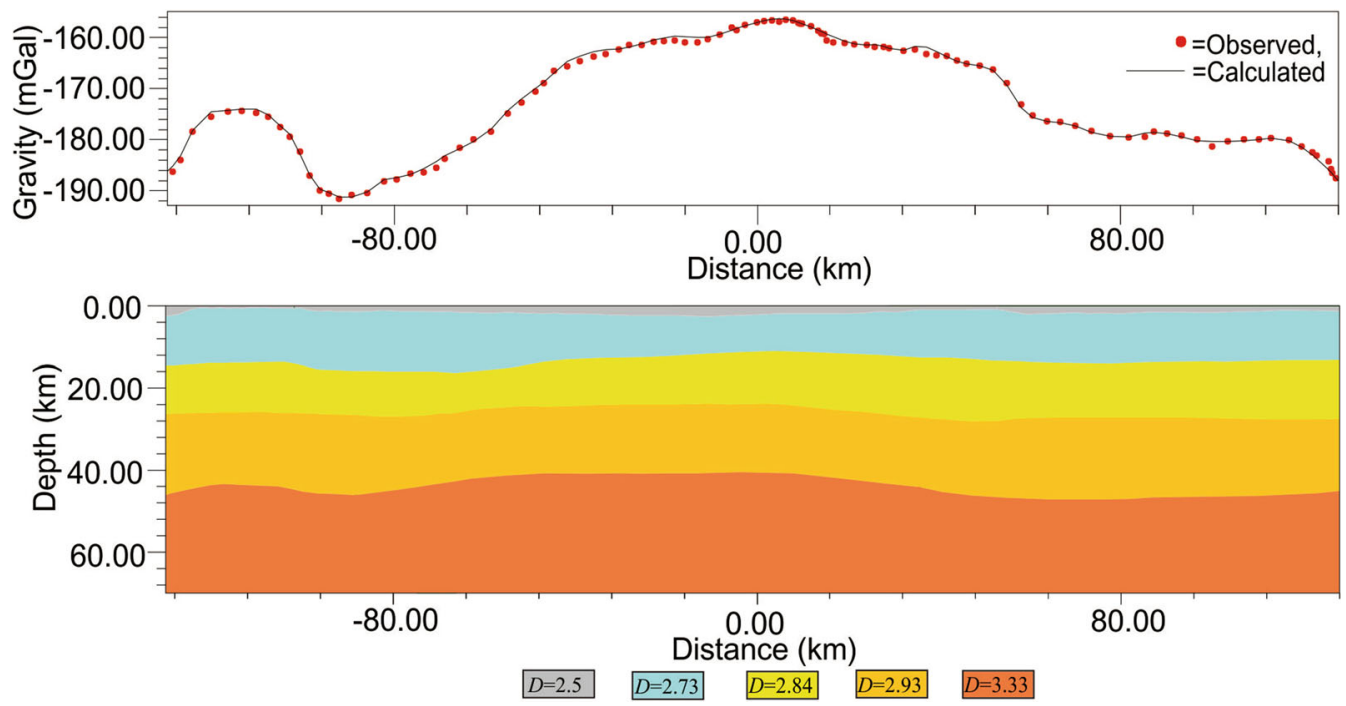

Fig. 5 Density structure of gravity profile along Suhaitu-Etuokeqi. The red points are observed values; the gray line is the value of the calculated fitting

\subsection{Relationship between crustal density layers and background dynamics}

The interpretation of the results of the Bouguer gravity anomaly of Suhait-Etuokeqi basically reflects different characteristics of the deep and shallow crustal internal structures. The results of the Bouguer gravity anomaly, the ratio of the elevation and the Bouguer anomaly, and NFG images show that the feature of horizontal partitioning and vertical stratification along the profile is significant. Therefore, combining with regional tectonic dynamics, this paper analyzes the crustal structure feature of two parts: two ends (the west and east part of the profile) and the middle (Yinchuan-Helanshan uplift-Jilantai rift zone).

The two ends (Alxa and Ordos block), the west and east parts of the profile, are located at the northeast of the Alxa block and the western margin of the Ordos block. From west to east, the images of the NGF and the density structure show that the crustal thickness gradually thins, and the $G^{h}$ value at both ends of the gravity profile is significantly higher than that in the Yinchuan-Helanshan uplift-Jilantai rift zone and forms a gradient zone in the North-East direction. This may be related to the blocking effect as the rigid Alxa and Ordos block obstructs the material of the northeast edge of the Qinghai-Tibet plateau flowing to the North-East. The ratio of elevation and the Bouguer anomaly shows that they are at a negative correlation, which can be explained by the Airy isostatic compensation hypothesis.

The middle part is the Yinchuan-Helanshan uplift-Jilantai rift zone. Compared with the Alxa block and the Ordos block, the Yinchuan-Helanshan uplift-Jilantai rift zone is "weak"; the material of the northeast edge of the Qinghai-Tibet plateau slides into this area and forms an arcuate structure. Where the
$G^{h}$ value is mainly low, there are several gradient zones that correspond to the faults, for example, $F 6, F 7, F 8$, and $F 9$. The density structure shows that the crustal thickness forms an uplift, with the crustal thickness shallowest near the Helanshan fault in this area. And the image of the ratio of the elevation and Bouguer anomaly shows that the degree of negative correlation in this section is different. That is to say, the material composition in the Earth's crust, density structure, and the layers of structure are different in this section. This can also be explained if the trend of the cut-off point or line is the large crustal deformation or a part with strong activity.

\subsection{Seismogenic structure of Pingluo $M 8$}

The long axis direction of magistoseismic area isoseismal line generally parallels to seismogenic fault strike, and the fault strike of $F 8$ is NNE; it is in accordance with the historical $M 8$ earthquake magistoseismic area long axis direction; the information of drilling and geology also shows that the largest subsidence area within the fault basin is near to $F 8$ since Pleistocene. At the same time, the image of the NFG along the gravity profile shows that there is a west-dipping gradient zone that is related to $F 8$. The epicenter of the projection of $M 8$ in 1739 is at about $15 \mathrm{~km}$ and intersects to $F 8$. The phenomenon shows that the seismogenic structure of Pingluo $M 8$ should be $F 8$ rather than $F 6$ and its focal depth is about $15 \mathrm{~km}$.

\section{Conclusions}

From the foregoing results of the gravity profile interpretation, the basic framework of the crust is nearly 
horizontally layered. The regional gravity anomaly distribution, the characteristics of the deep crust, and tectonic dynamics environment were studied and give the following results:

1. Moho depth trends and Bouguer gravity anomaly distribution are similar, that is to say, the main element of the Bouguer gravity anomaly is the regional field generated by the Moho fluctuation.

2. The distribution characteristics of the NFG image are connected with the faults. In this paper, the gradient zone of the NFG is mainly related to the major deep fracture zones. The transition zones of the NFG are consistent with the distribution of faults and their dip angles also coincide with each other along the SuhaituEtuokeqi profile, especially $F 1, F 6, F 7, F 8$, and $F 9$.

3. The elevation and Bouguer anomaly have a generally negative correlation in the profile, which means that the quality is an overall loss from Suhait to Etuokeqi. The ratio of ups and downs is large between $F 4$ and $F 6$, this can be explained by the fact that the crustal material is inhomogeneous and different in this section; this may be related to the pushing of the Qinghai-Tibet block in the northeast.

4. The seismogenic structure of Pingluo $M 8$ should be the Yinchuan blind fault rather than $F 6$ and its focal depth is about $15 \mathrm{~km}$.

Acknowledgments This work is supported by the Key Projects of China Seismic Array (201308011) and Earthquake Science (201508006), and the China Earthquake Administration, Institute of Seismology Foundation (201326126).

Open Access This article is distributed under the terms of the Creative Commons Attribution 4.0 International License (http://crea tivecommons.org/licenses/by/4.0/), which permits unrestricted use, distribution, and reproduction in any medium, provided you give appropriate credit to the original author(s) and the source, provide a link to the Creative Commons license, and indicate if changes were made.

\section{References}

Abedi M, Hafizi MK, Norouzi GH (2012) 2D interpretation of selfpotential data using normalized full gradient, a case study: galena deposit. Bollettino di Geofisica Teoricaed Applicata 53(2):213-230

Aghajani H, Moradzadeh A, Zeng H (2009) Normalized Full Gradient of Gravity Anomaly method and its application to the Mobrun Sulfide Body, Canada. World Appl Sci J 6(3):393-400

Berezkin VM (1967) Application of the total vertical gradient of gravity for determination of the depths to the sources of gravity anomalies. Explor Geophys 18:69-79

Berezkin VM, Buketov AP (1965) Application of the harmonical analysis for the interpretation of gravity data. Appl Geophys 46:161-166
Chai CZ, Meng GK, Du P, Wang Y, Liu BJ, Shen WH, Lei QY, Liao YH, Zhao CB, Feng SY, Zhang XH, Xie XF (2006) Comprehensive multi-level exploration of buried active fault: an example of Yinchuan buried active fault. Seismol Geol 28(4):536-544 (in Chinese with English abstract)

Dondurur D (2005) Depth estimates for slingram electromagnetic anomalies from dipping sheet-like bodies by the normalized full gradient method. Pure Appl Geophys 162:2179-2195

Fang SM, Zhao CB, Chai CZ, Liu BJ, Feng SY, Liu MJ, Lei QY, Liu $\mathrm{H}$ (2009) Seismic evidence of crustal structures in the Yinchuan faulted basin. Chin J Geophys 52(7):1768-1775 (in Chinese with English abstract)

Halls HC, Mound J (1998) The McEwan lake fault: gravity evidence for a new structural element of the Kapuskasing zone. Can J Earth Sci 35(6):696-701

Hong Y, Zhang BT, Mao FY (1987) The Cenozoic tectonic evolution of the Great North China: two types of rifting and crustal necking in the Great North China and their tectonic implications. Tectonophysics 133:217-227

Lei QY, Chai CZ, Du P, Yu JX, Wang Y, Xie XF (2015) The seismogenic structure of the M8.0 Pingluo earthquake in 1739 . Seismol Geol 37(2):413-419

Li ML, Wan ZC (1984) Characteristics of the earthquake-generating structures for magnitude 8.0 Pingluoearthquake of 1739 and the process of its preparation. Seismol Geol 6(3):23-28 (in Chinese with English abstract)

Liu JH, Zhang PZ, Zhen DW, Wan JL, Wang WT, Du P, Lei QY (2010) Pattern and timing of late Cenozoic rapid exhumation and uplift of the Helan Mountain, China. Sci China Earth Sci 40(1):50-60 (in Chinese with English abstract)

Mao TE, Yao JL (1982) A preliminary discussion on the relationship of deep environment to seismicity in north-south seismic belt (its northern and middle sections), China. Seismol Geol 4(2):21-28 (in Chinese with English abstract)

Meng LS, Jiang XR, Zhang FH, Xia ED (1990) The crust structure and gravity profile of Yecheng, Xinjiang-Shi Quanchen, Tibet. Chin J Geophys 33(6):670-677 (in Chinese with English abstract)

Nitescu B, Halls HC (2002) A gravity profile across Southern Saganash lake fault: implication for the origin of the Kapuskasing structural zone. Can J Earth Sci 39(4):469-480

Peng C, Min Z (1985) Statistical analysis of relationship between gravity anomaly and elevation. Geophys Geochem Explor 9(5):15-22 (in Chinese with English abstract)

Sindirgi P, Pamukc UO, Özyalin S (2008) Application of normalized full gradient method to self potential (SP) data. Pure Appl Geophys 165:409-427

Tongen M, Jialiu Y (1982) A preliminary discussion on the relationship of deep environment to seismic in North-south seismic belt (its northern and middle sections), China. Seismol Geol 4(2):21-31 (in Chinese with English abstract)

Wang QS, Wu CZ, Jiang WW (1997a) Gravity field and crustal structure of Gyirong-Lugu Region in western Xizang (Tibet) Plateau. Chin Sci Bull 42(8):669-673

Wang QS, Wu CZ, Jiang WW (1997b) Gravitational field and crustal structure in the Jilong-Lugu region western the Tibetan plateau. Chin Sci Bull 42(8):858-862 (in Chinese with English abstract)

Wang SJ, Wang FY, Zhang JS, Jia SX, Zhang CK, Zhao JR, Liu BF (2014) The P-wave velocity structure of the lithosphere of the North China craton-results from the Wendeng-Alxa left banner deep seismic sounding profile. Sci China Earth Sci 44(12):2697-2708 (in Chinese with English abstract)

Wang CY, Yang WC, Wu JP, Ding ZF (2015) Study on the lithospheric structure and earthquakes in North-South tectonic 
belt. Chin J Geophys 58(11):3867-3901 (in Chinese with English abstract)

Wu GJ, Shen CY, Tan HB, Yang GL (2015) Tectonic implication of images of Bouguer gravity anomaly and its normalized total gradient in 2015 A'lashanzuoqi $M_{\mathrm{S}} 5.8$ area. J Geod Geodyn 35(6):936-940 (in Chinese with English abstract)

Xu ZH, Wang SY, Gao AJ (2000) Present-day tectonic movement in the northeastern margin of the Qinghai-Xizang(Tibetan) Plateau as revealed by earthquake activity. Acta Seismol Sin 22(5):472-481 (in Chinese with English abstract)

Yang GL, Shen CY, Wu GJ, Tan HB, Shi L, Wang J, Zhang P, Wang JP (2015) Bouguer gravity anomaly and crustal density structure in Jinchuan-Lushan-Qianwei profile. Chin J Geophys 58(7):2424-2435 (in Chinese with English abstract)
Yin A, Harrison TM (2000) Geologic evolution of the HimalayanTibetan Orogen. Annu Rev Earth Planet Sci 28:211-280

Yin BX, Cheng JH, Min G, Cai XL, Yang Y (2013) The conductivity characteristics of middle and upper crust of Jingyuan-Yanchi, Southern Ningxia arc structure. Earth Sci Front 20(4):332-339 (in Chinese with English abstract)

Zhang PZ, Shen ZK, Wang M, Gan WJ, Burgmann Roland, Molnar Peter, Wang Q, Niu ZJ, Sun JZ, Wu JC, Sun HR, You XZ (2004) Continuous deformation of the Tibetan Plateau from global positioning system data. Geology 32(9):809-812

Zheng J (2011) The research on electric structure in Ordos and its relationship between geological structure. Master Dissertation. China University of Geosciences, Beijing (in Chinese with English abstract) 